\title{
Partially covered self-expandable metal stents versus polyethylene stents for malignant biliary obstruction: A cost-effectiveness analysis
}

\author{
Alan N Barkun MD MSc ${ }^{1,2}$, Viviane Adam MSc ${ }^{1}$, Myriam Martel BSc${ }^{1}$, Khalid AINaamani MD BSc ${ }^{3}$, Peter L Moses MD ${ }^{4}$
}

AN Barkun, V Adam, M Martel, K AlNaamani, PL Moses. Partially covered self-expandable metal stents versus polyethylene stents for malignant biliary obstruction: A cost-effectiveness analysis. Can J Gastroenterol Hepatol 2015;29(7):377-383.

BACKGROUND/OBJECTIVE: Partially covered self-expandable metal stents (SEMS) and polyethylene stents (PES) are both commonly used in the palliation of malignant biliary obstruction. Although SEMS are significantly more expensive, they are more efficacious than PES. Accordingly, a cost-effectiveness analysis was performed.

METHODS: A cost-effectiveness analysis compared the approach of initial placement of PES versus SEMS for the study population. Patients with malignant biliary obstruction underwent an endoscopic retrograde cholangiopancreatography to insert the initial stent. If the insertion failed, a percutaneous transhepatic cholangiogram was performed. If stent occlusion occurred, a PES was inserted at repeat endoscopic retrograde cholangiopancreatography, either in an outpatient setting or after admission to hospital if cholangitis was present. A third-party payer perspective was adopted. Effectiveness was expressed as the likelihood of no occlusion over the one-year adopted time horizon. Probabilities were based on a contemporary randomized clinical trial, and costs were issued from national references. Deterministic and probabilistic sensitivity analyses were performed.

RESULTS: A PES-first strategy was both more expensive and less efficacious than an SEMS-first approach. The mean per-patient costs were US\$6,701 for initial SEMS and US\$20,671 for initial PES, which were associated with effectiveness probabilities of $65.6 \%$ and $13.9 \%$, respectively. Sensitivity analyses confirmed the robustness of these results.

CONCLUSION: At the time of initial endoscopic drainage for patients with malignant biliary obstruction undergoing palliative stenting, an initial SEMS insertion approach was both more effective and less costly than a PES-first strategy.

Key Words: Biliary obstruction; Cost-effectiveness; Gastrointestinal cancer; Stent

The management of patients with malignant biliary obstruction 1 (MBO) focuses significantly on the relief of patient symptoms achieved with endoscopic drainage using different stent technologies $(1,2)$. Polyethylene stents (PES) remain widely used, even though the newer self-expandable metal stent (SEMS) types have demonstrated improved efficacy $(2,3)$, both covered and uncovered (4-7).

Although there are many reasons for their continued popularity, the choice of PES in the palliation of distal MBO is, no doubt, in part explained by its ease of insertion and favourable upfront cost compared with SEMS (8), with little consideration for downstream expenses attributable to differences in efficacy. Several previous analyses have

\author{
Les endoprothèses de métal auto-expansibles \\ partiellement couvertes par rapport aux \\ endoprothèses de polyéthylène en cas d'obstruction \\ biliaire maligne : une analyse coût-efficacité
}

HISTORIQUE ET OBJECTIF : Les endoprothèses de métal autoexpansibles (EMAE) partiellement couvertes et les endoprothèses de polyéthylène (EPÉ) sont toutes deux souvent utilisées pour pallier une obstruction biliaire maligne. Même si les EMAE sont beaucoup plus coûteuses, elles sont plus efficaces que les EPÉ. C'est pourquoi les chercheurs ont effectué une analyse coût-efficacité.

MÉTHODOLOGIE : Dans une analyse coût-efficacité, les chercheurs ont comparé l'EPÉ initiale à l'EMAE initiale auprès de la population à l'étude. Les patients ayant une obstruction biliaire maligne ont subi une cholangiopancréatographie rétrograde endoscopique pour insérer la première endoprothèse. Si l'insertion échouait, ils subissaient une cholangiographie transhépatique percutanée. En cas d'occlusion de l'endoprothèse, une EPÉ était insérée à la reprise de la cholangiopancréatographie rétrograde endoscopique, soit en milieu ambulatoire, soit après l'hospitalisation pour cholangite. Les chercheurs ont adopté la perspective du tiers payeur. L'efficacité était exprimée comme la probabilité d'absence d'occlusion dans l'horizon prévu d'un an. Les probabilités reposaient sur un essai clinique aléatoire contemporain tandis que les coûts étaient extrapolés des références nationales. Les chercheurs ont effectué des analyses de sensibilité déterministes et probabilistes. RÉSULTATS : La stratégie d'installation d'une EPÉ initiale était à la fois plus coûteuse et moins efficace que celle de l'installation d'une EMAE initiale. Les coûts moyens par patient étaient de 6701 \$US pour l'EMAE initiale et de 20671 \$US pour l'EPÉ initiale, qui s'associaient à des probabilités d'efficacité de 65,6 \% et de 13,9\%, respectivement. Les analyses de sensibilité ont confirmé la validité des résultats.

CONCLUSION : Au drainage endoscopique initial chez les patients ayant une obstruction biliaire maligne qui se faisaient installer une endoprothèse palliative, l'insertion initiale d'une EMAE était à la fois plus efficace et moins coûteuse que celle d'une EPÉ.

suggested that SEMS were both clinically superior and more cost effective than PES, even though they do not prolong survival. Specifically, advantages of SEMS have been reported in selected health care settings and in patients with longer anticipated life expectancy $(5,9-14)$. However, even these conclusions have been questioned by some $(5,8)$. Since the publication of most of these reports, the advent of partially covered SEMS (15), coupled to the evolution of biliary endoscopic techniques $(16,17)$, now justifies a more contemporary cost-effectiveness analysis that is based on a contemporary randomized clinical trial (RCT) (6).

\footnotetext{
${ }^{1}$ Division of Gastroenterology; ${ }^{2}$ Division of Epidemiology, Biostatistics and Occupational Health, McGill University Health Centre, McGill University, Montreal,

Quebec; ${ }^{3}$ Division of Gastroenterology, Hepatology and Liver Transplantation, The Armed Forces Hospital, Muscat, Oman; ${ }^{4}$ Division of Gastroenterology and

Hepatology, University of Vermont, Burlington, Vermont, USA

Correspondence: Dr Alan N Barkun, Division of Gastroenterology, Room D7-346, 1650 Cedar Avenue, Montreal General Hospital site, McGill

University Health Centre, Montreal, Quebec H3G 1A4. Telephone 514-934-8233, fax 514-934-8531, e-mail alan.barkun@muhc.mcgill.ca

Received for publication June 5, 2014. Accepted March 17, 2015
} 


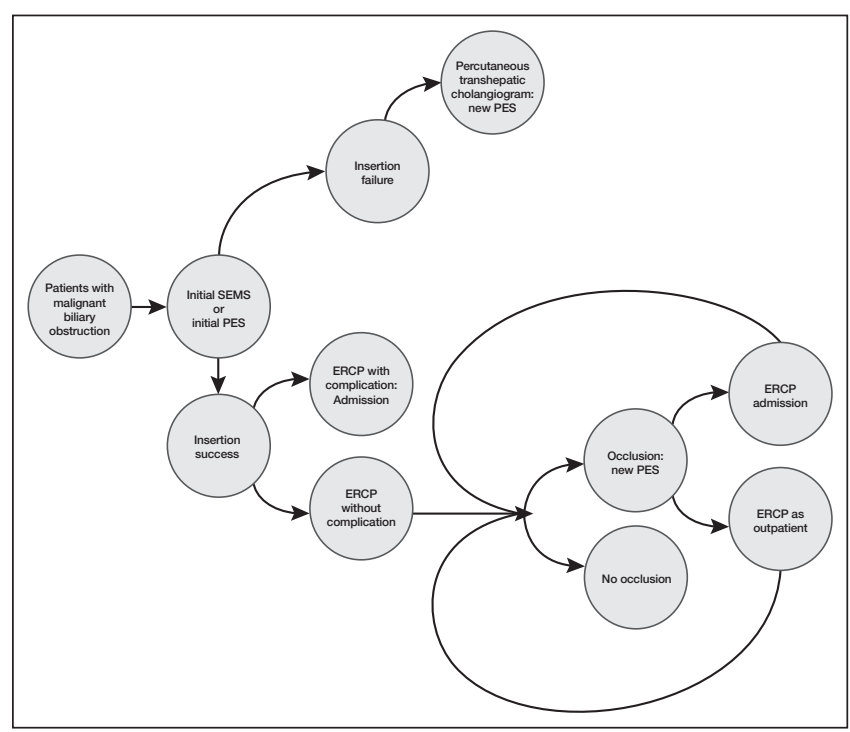

Figure 1) Influence diagram of the adopted model structure. ERCP Endoscopic retrograde cholangiopancreatography; PES Polyethylene stent; SEMS Partially covered self-expandable metal stent

\section{Overview}

\section{METHODS}

An incremental cost-effectiveness decision tree to compare the use of initial PES versus initial SEMS using TreeAge Pro Suite Healthcare module 2015 (18) for palliative patients deemed inoperable with MBO during a 12-month follow-up period was constructed. The outcome was the cost per stent occlusion averted. A third-party-payer perspective was adopted.

\section{Model design}

Although the RCT included one-, three-, six-, nine- and 12-month visits following randomization, these were not included in the basecase analysis because they would represent closer follow-up than in a real-life setting. At the beginning of the model, in each branch, after a first consultation an endoscopic retrograde cholangiopancreatography (ERCP) is performed to insert initially either a PES (initial PES) or an SEMS (initial SEMS). If the insertion fails, a percutaneous transhepatic cholangiogram (PTC) is performed, and it is the end of the model for this path. Figure 1 illustrates the structure of the model across a 12 -month time horizon following randomization. The model allows for a possible post-ERCP adverse event state as well (pancreatitis, cholangitis, bleeding). In follow-up, the only adverse event that was modelled for was the most common one of interval stent occlusion. The treatment of stent occlusion correspondingly required a stent change to a PES, either on an outpatient basis or with an admission to hospital because of associated cholangitis. Stent occlusion could occur between each planned outpatient visit at any time over the 12 -month time frame, termed time horizon. After the 12 months, the patient arrives at a terminal node and a cost per no occlusion is computed by the model for each branch. No patient death node was specifically included in the structure of the model.

\section{Probabilities}

The probabilities of failure of stent insertion (initial SEMS or initial PES) were extracted from the literature (2). All other probabilities in the model were based on a contemporary RCT of 85 patients comparing PES to SEMS (6). The inclusion criteria applied in this RCT are listed in Table 1 . All of the probabilities used in the model are listed in Table 2.

\section{Costs and lengths of stay}

The national United States (US) market price of the two types of stents used for PTC or ERCP were provided by Boston Scientific, USA (19).
TABLE 1

Inclusion and exclusion criteria

\section{Inclusion criteria}

Age $\geq 18$ years

Extrahepatic biliary obstruction by any malignant process, extending no more proximal than $1 \mathrm{~cm}$ below the common hepatic ductal bifurcation, as measured at the time of enrollment endoscopic retrograde cholangiopancreatography

A Karnofsky Performance Scale Index $>60 \%$

Patient physically capable and mentally willing to comply with the protocol requirements including stent insertion as well as the required threemonthly clinical follow-up visits

Signed voluntary informed consent

\section{Exclusion criteria}

Jaundice secondary to primary intrahepatic biliary obstruction (eg, patient had underlying chronic liver disease)

Active cholangitis

International normalized ratio $>3.0$

Multiple strictures requiring therapy

Biliary anatomy inappropriate for the available sizes of the biliary stents used in the study

Previous attempt at curative surgical resection of the malignant obstructing tumour

Patient has participated in a protocol involving an investigational drug or device 90 days before proposed entry into the present study

Allergy to any component of the individual stents, or their materials/delivery systems

Active alcohol or drug abuse

Unstable social circumstances that may preclude follow-up

Inability to understand and execute informed consent

All physicians fees were derived from the national database of the American Medical Association (20). Cost of hospitalization for cholangitis was based on specific admissions included in the Nationwide Inpatient Sample (NIS) 2008 (21). This national hospitalization database comprises eight million hospitalizations occurring in $>1000$ different hospitals located in 42 states of the US. Hospitalizations of patients who died during the hospital stay or who were $<18$ years of age were excluded from the analysis. Only hospitalizations that were recorded with Medicare, Medicaid or a private insurance as the primary payer were included. All the charges associated with the International Classification of Diseases 9-CM code '576.1: cholangitis' were selected. Costs were computed based on the average charges combined with a cost-to-charge ratio, which was, for the most part, specific to the hospital where the hospitalization took place; if not, a recommended (22) group average cost-to-charge ratio was applied. To obtain valid national cost estimates, discharge weights were used in the computations. The short time horizon of 12 months covering the entire study adopted obviates the need for discounting. All dollar values were expressed in 2014 US dollars utilizing the consumer price index for the medical care services published by the US Department of Labor (23). Indirect costs were not considered in the present analysis. All cost and length of stay estimates are presented in Table 3.

\section{Cost-effectiveness analysis}

The effectiveness is expressed as the probability of maintained patency occurring over the full duration of the model (one year with successful initial stent insertion). The costs are the sum of the cost items listed for all the 12 months. Results of the deterministic analysis are reported as cost, effectiveness, cost-effectiveness ratio and incremental costeffectiveness ratio (ICER).

Sensitivity and threshold analyses

Deterministic and probabilistic sensitivity analyses were performed. All bounds used for the sensitivity analyses of the probabilities were 
TABLE 2

Probability estimates of the model

\begin{tabular}{|c|c|c|c|}
\hline \multirow[b]{2}{*}{ Description of probability } & \multirow{2}{*}{$\begin{array}{c}\text { Point } \\
\text { estimate }\end{array}$} & \multicolumn{2}{|c|}{ Bound } \\
\hline & & Low & High \\
\hline \multicolumn{4}{|l|}{ Initial polyethylene stent } \\
\hline Failure of insertion at baseline & 0.05 & 0.02 & 0.09 \\
\hline Cholangitis before 1 month and before first occl & 0.195 & 0.102 & 0.34 \\
\hline Cholangitis before 1 month and after first occl & 0.286 & 0.082 & 0.641 \\
\hline Cholangitis between 1 and 3 months & 0.25 & 0.0456 & 0.699 \\
\hline Cholangitis between $>3$ and 6 months & 0.286 & 0.082 & 0.641 \\
\hline Cholangitis between $>6$ and 9 months & 0 & 0 & 0.5 \\
\hline Cholangitis between $>9$ and 12 months & 1 & 0.342 & 1 \\
\hline Occl before 1 month & 0.171 & 0.085 & 0.313 \\
\hline Occl between 1 and 3 months & 0.138 & 0.055 & 0.306 \\
\hline Occl between $>3$ and 6 months & 0.411 & 0.216 & 0.64 \\
\hline Occl between $>6$ and 9 months & 0 & 0 & 0.435 \\
\hline Occl between $>9$ and 12 months & 0.667 & 0.208 & 0.939 \\
\hline \multicolumn{4}{|c|}{ Initial partially covered self-expandable metal stent } \\
\hline Failure of insertion at baseline & 0.0597 & 0.03 & 0.1 \\
\hline Cholangitis before 1 month and before first occl & 0.049 & 0.014 & 0.161 \\
\hline Cholangitis before 1 month and after first occl & 0.5 & 0.095 & 0.906 \\
\hline Cholangitis between 1 and 3 months & 0.5 & 0.095 & 0.906 \\
\hline Cholangitis between $>3$ and 6 months & 0 & 0 & 0.5 \\
\hline Cholangitis between $>6$ and 9 months & 0 & 0 & 0.5 \\
\hline Cholangitis between $>9$ and 12 months & 0 & 0 & 0.5 \\
\hline Occl before 1 month & 0.049 & 0.014 & 0.161 \\
\hline Occl between 1 and 3 months & 0.074 & 0.021 & 0.234 \\
\hline Occl between $>3$ and 6 months & 0.111 & 0.031 & 0.328 \\
\hline Occl between $>6$ and 9 months & 0 & 0 & 0.269 \\
\hline Occl between $>9$ and 12 months & 0.111 & 0.03 & 0.564 \\
\hline
\end{tabular}

Source of the probabilities: The two probabilities of failure of the insertion were issued from the literature (2). All the other probabilities were based on a randomized clinical trial whose patients were issued from the six participating North American university centres mentioned in the method section (6). The bounds for the sensitivity analysis were based on the $95 \%$ Cls. occl Occlusion

based on the 95\% CIs. The ranges for the length of stay and cost of an admission for cholangitis were based on the standard deviations of the NIS database (21). All other cost ranges were equal to the point estimates plus $100 \%$ or less $50 \%$.

One-way sensitivity analyses were performed on all variables used in the model to investigate the robustness of the results and to determine which factors influenced most these results.

A Tornado diagram was chosen to represent how the variation of the value of an input variable of the model across a pre-set range influences the results of the model. The widest bars of the Tornado diagram identify the variables that most changed the ICER (beyond 20\%). As part of the sensitivity analysis, the influence of the time horizon chosen on the model results was specifically assessed. Threshold analyses were also performed to observe the cut-off points for which the conclusion of the model could change. Probabilistic sensitivity analysis was performed running 10,000 Monte Carlo simulations based on the uncertainty distributions of all the variables and a chosen maximal willingness to pay (WTP) value of US\$50,000. A WTP represents the pre-fixed maximum dollar value that is deemed to be acceptable spending for a given treatment. Results of the probabilistic analysis are reported as an incremental cost-effectiveness scatter plot. It illustrates the probability that a stent is cost effective compared with the other one, given a WTP.

\section{RESULTS}

Base-case analysis

The report of the results (Table 4) shows that using initial SEMS over a period of 12 months for patients with $\mathrm{MBO}$ is a strategy significantly less expensive but also more efficacious; indeed, the initial SEMS
TABLE 3

Cost and length of stay (LOS) estimates of the model

\begin{tabular}{lcccc}
\hline Description of cost/ & Point & & \multicolumn{2}{c}{ Bound } \\
\cline { 4 - 6 } LOS variable & estimate & Source & Low & High \\
\hline Price of initial PES & 115 & BS (18) & 60 & 230 \\
Price of initial SEMS & 2,413 & BS (18) & 1000 & 5000 \\
Cost of outpatient follow-up & 83 & AMA (19) & 40 & 170 \\
Cost of inpatient follow-up & 107 & AMA (19) & 50 & 220 \\
Cost of outpatient first consultation & 139 & AMA (19) & 70 & 280 \\
Cost of inpatient first consultation & 122 & AMA (19) & 60 & 250 \\
Cost of emergency consultation & 66 & AMA (19) & 30 & 140 \\
Cost of physician fees PTC & 467 & AMA (19) & 230 & 940 \\
Cost of physician fees ERCP & 483 & AMA (19) & 240 & 970 \\
Cost of procedure PTC & 2,471 & BS (18) & 1200 & 5000 \\
Cost of procedure ERCP & 1,170 & BS (18) & 500 & 2400 \\
Cost of admission for cholangitis & 15,100 & NIS (20) & 5000 & 30,000 \\
LOS of cholangitis & 5.5 & NIS (20) & 1 & 12 \\
\hline All cost are
\end{tabular}

All costs are in 2014 United States dollars. The bounds for the sensitivity analysis were based on the SD for the LOS and cost of an admission for cholangitis. For all the other cost variables, the low (high) bounds were based on the point estimates divided (multiplied) by 2. AMA American Medical Association; BS Boston Scientific (USA); ERCP Endoscopic retrograde cholangiopancreatography; NIS National Inpatient Sample; PES Polyethylene stent; PTC Percutaneous transhepatic cholangiogram; SEMS Partially covered self-expandable metal stent

\section{TABLE 4}

Cost-effectiveness analysis report

\begin{tabular}{lcccccc}
\hline Stent & Cost & IC & Eff & IE & CER & ICER \\
\hline Initial SEMS & 6,701 & 0 & 0.6561 & 0 & 10,213 & 0 \\
Initial PES & 20,671 & 13,971 & 0.1385 & -0.5176 & 149,243 & Dominated $^{*}$ \\
\hline All
\end{tabular}

All costs are expressed in 2014 United States dollars. *Incremental costeffectiveness ratio (ICER) $=-$ US\$26,993. CER Cost-effectiveness ratio; Eff Effectiveness (probability of no occlusion during the consecutive 12 months); IC Incremental cost; IE Incremental effectiveness; PES Polyethylene stent; SEMS Partially covered self-expandable metal stent

approach dominates the initial PES strategy. On average, it would save US $\$ 13,971$ per patient to opt for the initial SEMS strategy while at the same time the patient would have a $50 \%$ decrease in probability of biliary stent occlusion during the 12 consecutive month follow-up after the index ERCP. Therefore, the average cost per no occlusion is significantly more attractive with initial SEMS (US\$10,213) than for initial PES (US\$149,243).

\section{Sensitivity analyses}

One-way deterministic sensitivity analyses: Any variable used in the model does not change the final choice of strategy: initial PES is always dominated, even if the point estimates vary inside their respective plausible ranges. The Tornado diagram (Figure 2) shows that within the plausible ranges of all the variables of the model, the cost of hospitalization for cholangitis most influences the ICER value. It is only when the variables are made to assume values outside their predetermined ranges that there is a change in the dominance of the SEMS approach. Indeed, threshold analysis shows that the cost of initial SEMS would have to increase above US $\$ 16,240$ for initial PES to be no longer dominated. The other threshold values for other variables are even less clinically plausible.

Regardless of the selected time horizon, the initial PES approach is still dominated by the initial SEMS approach (Figure 3). Adding the costs of three-monthly follow-up visits from the first to the 12th month (as in the RCT), do not alter the conclusion with a corresponding ICER of US $\$ 26,700$ and an average cost strategy of US $\$ 7,060$ (initial SEMS) versus US $\$ 20,880$ (initial PES). 


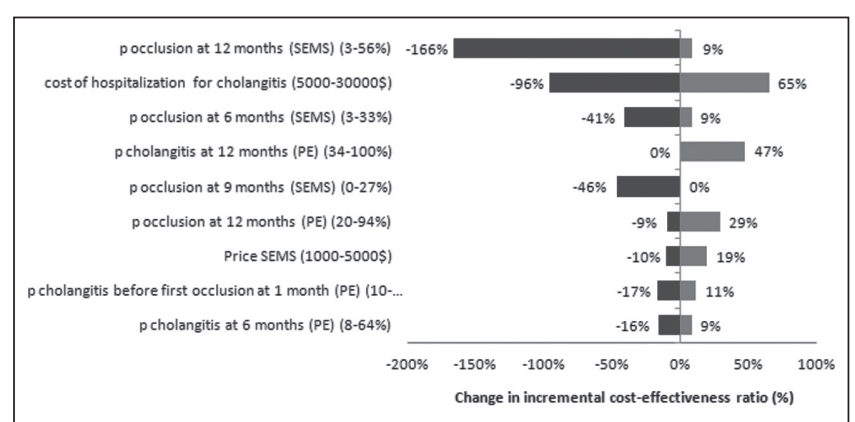

Figure 2) Tornado diagram for variations of $\geq 20 \%$ and from the base-case incremental cost-effectiveness ratio (ICER) estimate. p Probability of; PES Polyethylene stent; SEMS Partially covered self expandable metal stent

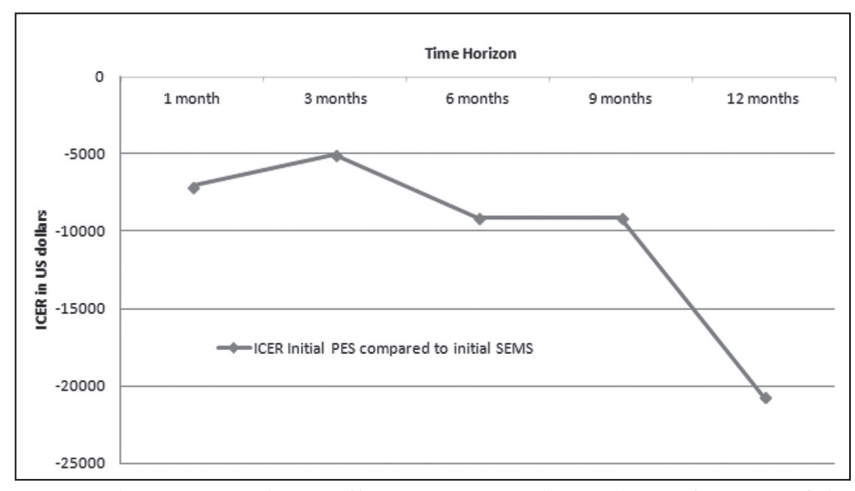

Figure 3) Incremental cost-effectiveness ratio (ICER) as a function of the adopted time horizon for the cost-effectiveness model. PES Polyethylene stent; SEMS Partially covered self-expandable metal stent

Probabilistic sensitivity analyses: The Monte-Carlo analysis was based on 10,000 simulations that each vary simultaneously all the variables of the model according across their adopted ranges. It represents the uncertainty about the estimates of costs and measure of effectiveness. The incremental cost-effectiveness scatter plot is presented in Figure 4: each point represents the incremental cost and effectiveness pair from the simulation results for initial SEMS relative to initial PES. The ellipse circumscribes $95 \%$ of the cloud of the results of cost and effectiveness points when simulations are performed according to the Monte Carlo analysis. All points below the WTP threshold are the simulation iterations where the initial SEMS is preferred given a WTP of US $\$ 50,000$ : they represent $90 \%$ of the 10,000 simulation iterations. It expresses the probabilities of preference for initial SEMS or PES, across a range of possible WTP threshold values. For every WTP threshold, the initial SEMS approach is the preferred management compared with initial PES.

\section{DISCUSSION}

The present analysis demonstrates the economic dominance of a SEMS-first approach with robust sensitivity analysis. Such a broad, overriding conclusion has not previously been adopted by other costeffectiveness analyses and, thus, warrants a discussion of our methodology and a review of the literature.

Considering the short clinically pertinent survival time and the outcome of 'cost per no occlusion', we adopted a cost-effectiveness decision tree approach whose structure was dictated by the RCT on which it is based (6). In accordance with the concept of a theoretical decision model, we simplified some possible events: initial insertion failures are immediately followed by a PTC and a final node. The outcomes of these few patients until the 12th month was not taken into account because it would not have any impact on our comparison; this group of patients is similar between both approaches. We considered

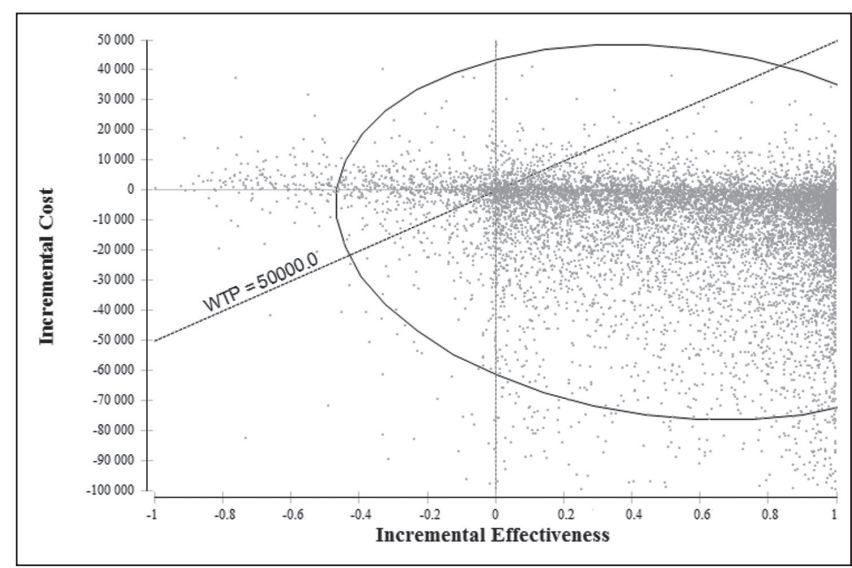

Figure 4) Incremental cost-effectiveness scatter plot of initial partially covered self-expandable metal stent (SEMS) versus initial polyethylene stent (PES). All costs expressed in 2014 United States dollars. The willingnessto-pay (WTP) threshold (US\$50,000) is the line that intersects the origin and the initial PES strategy is represented by the origin $(0 ; 0)$

the probability of all adverse events, but specifically modelled for the length of stay and costs attributable to bouts of cholangitis because it is by far the most common in this context (24); other authors have done similarly in past published economic analyses $(9,14)$. We chose not to include death in the measure of effectiveness because this outcome introduces a lot of uncertainty (in addition to the estimation of related costs). Finally, the literature has reported no difference in mortality when comparing the use of each of the two types of stents $(5,9,10,12-14,25,26)$.

Because the clinical trial data were available up to 12 months, it was, therefore, logical to fix the time horizon at one year, as has been performed in most cost-effectiveness analyses $(9,13,27)$. This chosen time horizon is also consistent with the median survival duration observed in recent cohorts of patients with $\mathrm{MBO}$ treated with metallic stents (28).

All efficacy assumptions were based on real outcomes information observed in a contemporary RCT comparing both stent technologies (6), an important decision that is supported by the evolution of biliary endoscopic techniques and contemporary supportive care in this patient group. Although such a choice of data source decreases the external validity of the point estimates, it allows for inclusion of more uniform and clinical, currently valid assumptions; in fact, five of the seven studies included in an authoritative meta-analysis by Moss et al (2) were $\geq 15$ years of age (2). Moreover, the RCT on which our analysis is based likely carries sufficient generalizability because patients were included from six participating North American university centres. The robustness of the cost variables of the model is based on the national representativeness of the recent data we used from the NIS 2008 (21) and that we updated for 2011, and are both, here too, more contemporary and more generalizable to a Western setting than many previous reports. In fact, as in efficacy information, many published cost analyses assessing malignant biliary stenting are significantly older, bringing into question the clinical relevance of those previous results. As examples, Prat et al (12) and Davids et al (25) based their analysis on costs markedly inferior to today's purchase costs (for example, US\$20 for PES); the SEMS, at that time, also referring to an uncovered stent technology. In addition, most published cost models have not assessed relevant estimates for a North American practice with US data, focusing rather on local national costs and currencies $(7,11,14,15,27,29)$. Other limitations are the inclusion in many analyses of sole stent costs without consideration other expenses $(5,13,29,30)$. The summary review by Moss et al (31) in 2007 computed cost-effectiveness results in which three of the four studies were published before the turn of the century; moreover, their ICER 
calculation is very approximate because it is based on the assumption that the stent price is the only difference between the two interventions. Because the patients included in the RCT (6) we used as reference were followed every three months during the study, we also added the cost of the follow-up visits from the first to the 12th month in another version of our base-case model. The comparison of the two approaches remained, however, in the same proportion.

The ICER was expressed as cost per occlusion (ie, ERCP) averted as was performed by Moss et al (31) and others $(25,29,32)$, rather than quality-adjusted life-year (QALY) as was performed by Arguedas et al (9), who recognized the limited reliability of this measure with the available information for palliative patients with $\mathrm{MBO}$. Furthermore, the ICERs expressed as cost per QALY are sometimes more difficult to interpret over short time horizons than if the ICER is based on outcomes reflecting more concrete end points. In such clinical contexts, the unit of efficacy can be chosen specific to the medical condition $(28,33-37)$, as has been the case for MBO $(11,12,14,25,27,29,31)$.

To confirm robustness of the results, we performed both deterministic and probabilistic sensitivity analyses consistent with existing methodological recommendations (38-41). The ranges of the probability variables were guided by the data from our RCT (6), while we used wide intervals for the cost estimates (Table 3), identifying only highly improbable, clinically irrelevant thresholds values. Because patient survival and time horizon are critical individual factors, we also assessed the impact of the duration of the time horizon, and tested the relevance of the adopted 12 months. Regardless of the time horizon chosen between one and 12 months, the initial SEMS approach remained dominant. The probabilistic sensitivity analysis leads to similar conclusions. Representative gastrointestinal disease literature have fixed values for WTP in the clinical context of gastrointestinal bleeding (33-37), gastroesophageal reflux disease (42) or adverse events in critically ill patients (43). However, we did not find reference to any set WTP that could apply to patients suffering from $\mathrm{MBO}$. In fact, the choice of a threshold for a WTP often remains subjective (37,44-46). An arbitrary WTP was therefore estimated at US\$50,000 based on the magnitude of the average cost of the treatment of occlusion, as suggested by Enns et al (37).

Our conclusions differ from most past economic analyses in that the increased cost effectiveness of a SEMS-first strategy (if not dominance) is found to apply regardless of patient survival or cost settings. A review of published cost analyses comparing plastic to metal stents in patients stented for distal MBO explain the reasons for such a disparity: other cost studies are derived from direct RCT results, comparing plastic with uncovered metal stents $(11,12,25,27)$. Three RCTs $(11,12,27)$ tabulated total costs, which were higher in the metal stent group, without calculating ICERs and without performing any sensitivity analysis. Moss et al (31) performed an extrapolated ICERs for these three studies $(11,12,27)$, based on the assumption that, in each individual trial, the only difference in unit costs between both interventions was the stent price. They concluded that uncovered SEMS had significantly higher patency rates than PES as early as four months after insertion. A later RCT by Kaassis et al (27) concluded that placement of a PES in a patient with hepatic metastases and a metal stent in patients without hepatic metastases was cost effective solely based on extrapolations of median survival data. Three more recent RCTs $(5,7,47)$ yielded direct cost analyses; however, once again, no modelling or sensitivity analyses were performed that recommended that the more effective uncovered SEMS be used in unresectable patients with malignant common bile duct strictures, who survived a median of 4.5 months, while less costly PES were preferable in the one-third of patients who have distant metastases.

Two true cost-effectivenesss analyses with appropriate modelling and sensitivity analyses were performed, both $>10$ years ago. In the first, Yeoh et al (13) concluded in 1999 that the choice of stent should be guided by the relative local costs of ERCP and metal stents, and by the prognosis of the patient, whereby metal stents were preferable for patients surviving $>4$ months. The authors, however, did not carry out a true cost-effectiveness analysis, as highlighted by others (9). Later in
2002, Arguedas et al (9) completed a very thorough and methodologically sound cost-effective analysis, with costs drawn from the University of Alabama (Birmingham, Alabama, USA) in 1999 and even considered the costs of home care, while using QALYs as the unit of effectiveness as discussed earlier. The authors concluded initial endoscopic placement of an uncovered metal stent was a cost-saving strategy compared to initial PES placement, particularly in patients expected to survive $>6$ months.

Principal differences between these previous cost-effective analyses and our own that explain the differences in findings include a higher incidence of cholangitis associated with stent obstruction in the plastic group of our recent RCT, and observed real-life probabilities at the different time points of follow-up. Moreover, as already suggested above, contemporary costs, including equipment and admissions to hospital are much greater (for example US\$8,333 in the Arguedas et al [9] analysis versus our US\$13,768, or the per diem of $€ 480$ in the Soderlund et al study (7) versus our US $\$ 2,500)$.

A more recent study by Hamada et al (15) compared a one-step versus an unusual two-step SEMS (covered and uncovered) insertion strategy in which a nasobiliary catheter is first inserted, while using local institutional charges. They concluded on the superiority of a SEMS-first approach but did not perform sensitivity analyses.

Because the majority of biliary stents inserted worldwide remain PES, an effort will need to be made to consider using the SEMS technology at the initial endoscopic procedure. In fact, decision makers need to consider the downstream cost effectiveness of an approach as opposed to the upfront cost of a piece of equipment.

Limitations of our analysis include the realization that many of the probabilities we used are based on small groups of patients whose numbers decrease gradually as patients flow through the 12-month trial duration, including complication rates (although sensitivity analyses include broad published ranges of these). The probability values in the last months of the model are therefore the most uncertain. It is also possible that very discreet subgroups of patients may benefit from an initial PES insertion; however, this appears to be unlikely based on the robustness and generalizability imparted by the uniform findings on multiple sensitivity analyses in our study. Also, the RCT data are principally based on $10 \mathrm{~mm}$ partially covered SEMS and $10 \mathrm{Fr}$ plastic stents. Moreover, the SEMS technology adopted for the present cost analysis was that of a partially covered stent; however, the relative efficacy of covered versus uncovered SEMS remains controversial $(1,48)$. It is important to note that partially covered SEMS are more expensive than uncovered SEMS and these latter stents are commonly used in clinical practice. Therefore, had the model included uncovered SEMS they may have been the preferred strategy and, at a minimum, partially covered SEMS would most likely not have been dominant. Similarly, because of the source data for this analysis, other relevant comparators were not assessed and this is a limitation. The costs adopted are US-based and reflect not only US currency but also a US fee structure; this realization needs to be kept in mind when the results are generalized to a Canadian setting. Moreover, our data, based on palliative patients, do not allow us to confidently conclude on the choice of stent for temporary biliary drainage while awaiting a possible curative surgery as has been increasingly practiced, with some surgeons preferring initial plastic stent insertion. Two recent cost-minimization studies examining in part this issue suggest the cost effectiveness of covered SEMS over PES and/or DoubleLayer PES $(10,30)$, although a policy of routine preoperative drainage has not been shown to improve and may even worsen subsequent outcomes (48-50).

DISCLOSURES: Dr Alan Barkun has served as consultant for Olympus and Cook; speaker for AstraZeneca, and has received research funding from Cook and Boston Scientific. Viviane Adam, Myriam Martel and Dr Peter Moses have no conflict of interest to declare. The sponsor participated in no aspects of study design, data collection, analysis or the interpretation of the results. Nor did they participate in any way in the writing of the report, nor in the decision to submit the manuscript for publication. 


\section{CONCLUSION}

Using a cost-effectiveness analysis modelled principally based on a recent RCT, a PES-first strategy was both more expensive and less efficacious than that of a SEMS-first approach in palliating patients with distal MBO. The average cost was US $\$ 6,701$ for the SEMS-first and US $\$ 20,674$ for PES-first, and associated with effectiveness probabilities of experiencing no occlusion over the 12 months of $65.6 \%$ and $13.9 \%$, respectively. Extensive sensitivity analyses confirmed the robustness of these conclusions. The present analysis, based on contemporary estimates of both effectiveness and costs, expands on previous, now less-pertinent costeffectiveness analyses, suggesting that in 2013, at the time of initial endoscopic drainage for patients with $\mathrm{MBO}$ undergoing palliative stenting, insertion of a partially covered SEMS is thus both more effective and less costly than that of a PES, regardless of anticipated survival or cost settings.

\section{REFERENCES}

1. Almadi MA, Barkun AN, Martel M. No benefit of covered vs uncovered self-expandable metal stents in patients with malignant distal biliary obstruction: a meta-analysis. Clin Gastroenterol Hepatol 2013;11:27-37,e21.

2. Moss AC, Morris E, Mac Mathuna P. Palliative biliary stents for obstructing pancreatic carcinoma. Cochrane Database Syst Rev 2006(2):CD004200.

3. Hong WD, Chen XW, Wu WZ, Zhu QH, Chen XR. Metal versus plastic stents for malignant biliary obstruction: An update metaanalysis. Clin Res Hepatol Gastroenterol 2013;37:496-500.

4. Isayama H, Yasuda I, Ryozawa S, et al. Results of a Japanese multicenter, randomized trial of endoscopic stenting for nonresectable pancreatic head cancer (JM-test): Covered Wallstent versus DoubleLayer stent. Dig Endosc 2011;23:310-5.

5. Katsinelos P, Paikos D, Kountouras J, et al. Tannenbaum and metal stents in the palliative treatment of malignant distal bile duct obstruction: A comparative study of patency and cost effectiveness. Surg Endosc 2006;20:1587-93.

6. Moses PL, Alnaamani KM, Barkun AN, et al. Randomized trial in malignant biliary obstruction: Plastic vs partially covered metal stents. World J Gastroenterol 2013;19:8638-46.

7. Soderlund C, Linder S. Covered metal versus plastic stents for malignant common bile duct stenosis: A prospective, randomized, controlled trial. Gastrointest Endosc 2006;63:986-95.

8. Levy MJ, Baron TH, Gostout CJ, Petersen BT, Farnell MB. Palliation of malignant extrahepatic biliary obstruction with plastic versus expandable metal stents: An evidence-based approach. Clin Gastroenterol Hepatol 2004;2:273-85.

9. Arguedas MR, Heudebert GH, Stinnett AA, Wilcox CM. Biliary stents in malignant obstructive jaundice due to pancreatic carcinoma: A cost-effectiveness analysis. Am J Gastroenterol 2002;97:898-904.

10. Kahaleh M, Brock A, Conaway MR, et al. Covered self-expandable metal stents in pancreatic malignancy regardless of resectability: A new concept validated by a decision analysis. Endoscopy. 2007;39:319-24.

11. Knyrim K, Wagner HJ, Pausch J, Vakil N. A prospective, randomized, controlled trial of metal stents for malignant obstruction of the common bile duct. Endoscopy 1993;25:207-12.

12. Prat F, Chapat O, Ducot B, et al. A randomized trial of endoscopic drainage methods for inoperable malignant strictures of the common bile duct. Gastrointest Endosc 1998;47:1-7.

13. Yeoh KG, Zimmerman MJ, Cunningham JT, Cotton PB. Comparative costs of metal versus plastic biliary stent strategies for malignant obstructive jaundice by decision analysis. Gastrointest Endosc 1999;49(4 Pt 1):466-71.

14. Yoon WJ, Ryu JK, Yang KY, et al. A comparison of metal and plastic stents for the relief of jaundice in unresectable malignant biliary obstruction in Korea: An emphasis on cost-effectiveness in a country with a low ERCP cost. Gastrointest Endosc 2009;70:284-9.

15. Hamada T, Nakai Y, Isayama H, et al. One- and two-step selfexpandable metal stent placement for distal malignant biliary obstruction: A propensity analysis. J Gastroenterol 2012;47:1248-56.
16. Isayama H, Nakai Y, Kawakubo K, et al. Endoscopic retrograde cholangiopancreatography for distal malignant biliary stricture. Gastrointest Endosc Clin N Am 2012;22:479-90.

17. Ridtitid W, Rerknimitr R. Management of an occluded biliary metallic stent. World J Gastrointest Endosc 2012;4:157-61.

18. TreeAge Software Inc. Healtcare Module. Williamstown: USA 2015. <www.treeage.com/> (Accessed March 2015).

19. Boston Scientific. <www.bostonscientific.com/home.bsci> (Accessed March 2015).

20. American Medical Association. <www.ama-assn.org/> (Accessed March 2015).

21. Nationwide Inpatient Sample (NIS) 2008. Healthcare Cost and Utilization Project. <www.hcup-us.ahrq.gov/databases.jsp> (Accessed March 2015).

22. HCUP. Introduction to the HCUP Nationwide Inpatient Sample 2008: Agency of Healthcare Research and Quality Project $\mathrm{HCaU} ; 2010$.

23. U.S. Bureau of Labor Statistics. <www.bls.gov/> (Accessed March 2015).

24. Chan G, Barkun J, Barkun AN, et al. The role of ciprofloxacin in prolonging polyethylene biliary stent patency: A multicenter, doubleblinded effectiveness study. J Gastrointest Surg 2005;9:481-8.

25. Davids PH, Groen AK, Rauws EA, Tytgat GN, Huibregtse K. Randomised trial of self-expanding metal stents versus polyethylene stents for distal malignant biliary obstruction. Lancet 1992;340:1488-92.

26. Mukai T, Yasuda I, Nakashima M, et al. Metallic stents are more efficacious than plastic stents in unresectable malignant hilar biliary strictures: a randomized controlled trial. J Hepatobiliary Pancreat Sci 2013;20:214-22.

27. Kaassis M, Boyer J, Dumas R, et al. Plastic or metal stents for malignant stricture of the common bile duct? Results of a randomized prospective study. Gastrointest Endosc 2003;57:178-82.

28. Pola S, Muralimohan R, Cohen B, Fehmi SM, Savides TJ. Longterm risk of cholangitis in patients with metal stents for malignant biliary obstruction. Dig Dis Sci 2012;57:2693-6.

29. Schmassmann A, von Gunten E, Knuchel J, et al. Wallstents versus plastic stents in malignant biliary obstruction: Effects of stent patency of the first and second stent on patient compliance and survival. Am J Gastroenterol 1996;91:654-9.

30. Chen VK, Arguedas MR, Baron TH. Expandable metal biliary stents before pancreaticoduodenectomy for pancreatic cancer: A Monte-Carlo decision analysis. Clin Gastroenterol Hepatol 2005;3:1229-37.

31. Moss AC, Morris E, Leyden J, MacMathuna P. Do the benefits of metal stents justify the costs? A systematic review and meta-analysis of trials comparing endoscopic stents for malignant biliary obstruction. Eur J Gastroenterol Hepatol 2007;19:1119-24.

32. Tham TC, Carr-Locke DL, Vandervoort J, et al. Management of occluded biliary Wallstents. Gut 1998;42:703-7.

33. Al-Sabah S, Barkun AN, Herba K, et al. Cost-effectiveness of proton-pump inhibition before endoscopy in upper gastrointestinal bleeding. Clin Gastroenterol Hepatol 2008;6:418-25.

34. Barkun AN, Adam V, Sung JJ, et al. Cost effectiveness of high-dose intravenous esomeprazole for peptic ulcer bleeding. Pharmacoeconomics 2010;28:217-30.

35. Barkun AN, Herba K, Adam V, et al. The cost-effectiveness of high-dose oral proton pump inhibition after endoscopy in the acute treatment of peptic ulcer bleeding. Aliment Pharmacol Ther 2004;20:195-202.

36. Barkun AN, Herba K, Adam V, et al. High-dose intravenous proton pump inhibition following endoscopic therapy in the acute management of patients with bleeding peptic ulcers in the USA and Canada: A cost-effectiveness analysis. Aliment Pharmacol Ther 2004;19:591-600.

37. Enns RA, Gagnon YM, Rioux KP, Levy AR. Cost-effectiveness in Canada of intravenous proton pump inhibitors for all patients presenting with acute upper gastrointestinal bleeding. Aliment Pharmacol Ther 2003;17:225-33.

38. Guidelines for the Economic Evaluation of Health Technologies: Canada: Ottawa: Canadian Agency for Drugs and Technologies in Health, 3rd edn, 2006.

39. Guide to the Methods of Technology Appraisal: National Institute for Health and Clinical Excellence: June 2008.

40. A format for submission of clinical and economic evidence of pharmaceuticals in support of formulary consideration: Foundation 
for Managed Care Pharmacy - Academy of Managed Care Pharmacy, 2009.

41. Drummond MF, Jefferson TO. Guidelines for authors and peer reviewers of economic submissions to the BMJ. The BMJ Economic Evaluation Working Party. BMJ 1996;313:275-83.

42. Briggs AH, Goeree R, Blackhouse G, O’Brien BJ. Probabilistic analysis of cost-effectiveness models: Choosing between treatment strategies for gastroesophageal reflux disease. Med Decis Making 2002;22:290-308.

43. Barkun AN, Adam V, Martel M, Bardou M. Cost-effectiveness analysis: Stress ulcer bleeding prophylaxis with proton pump inhibitors, $\mathrm{H}_{2}$ receptor antagonists. Value Health 2013;16:14-22.

44. Ubel PA, Hirth RA, Chernew ME, Fendrick AM. What is the price of life and why doesn't it increase at the rate of inflation? Arch Intern Med 2003;163:1637-41.

45. Ariely D. Predictably Irrational: The Hidden Forces that Shape our Decisions. 1st Harper Perennial edn. New York: Harper Perennial; 2010.
46. Weintraub WS, Cohen DJ. The limits of cost-effectiveness analysis. Circ Cardiovasc Qual Outcomes 2009;2:55-8.

47. Isayama $\mathrm{H}$, Komatsu $\mathrm{Y}$, Tsujino $\mathrm{T}$, et al. A prospective randomised study of "covered" versus "uncovered" diamond stents for the management of distal malignant biliary obstruction. Gut 2004;53:729-34

48. Saleh MM, Norregaard P, Jorgensen HL, Andersen PK, Matzen P. Preoperative endoscopic stent placement before pancreaticoduodenectomy: A meta-analysis of the effect on morbidity and mortality. Gastrointest Endosc 2002;56:529-34.

49. Sewnath ME, Karsten TM, Prins MH, et al. A meta-analysis on the efficacy of preoperative biliary drainage for tumors causing obstructive jaundice. Ann Surg 2002;236:17-27.

50. van der Gaag NA, Rauws EA, van Eijck CH, et al. Preoperative biliary drainage for cancer of the head of the pancreas. N Engl J Med 2010;362:129-37. 


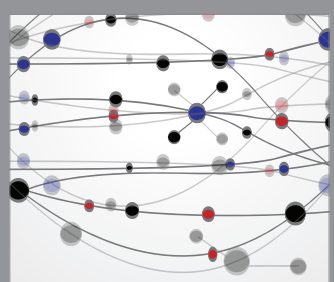

The Scientific World Journal
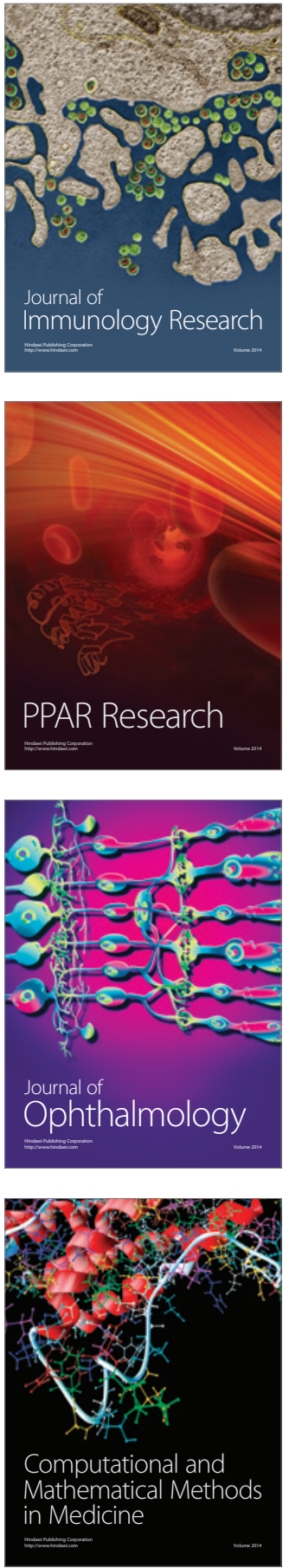

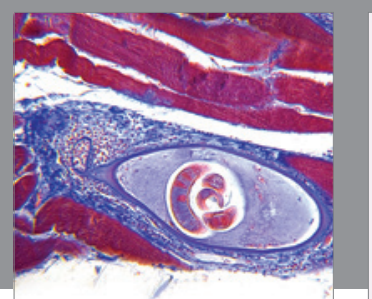

Gastroenterology Research and Practice

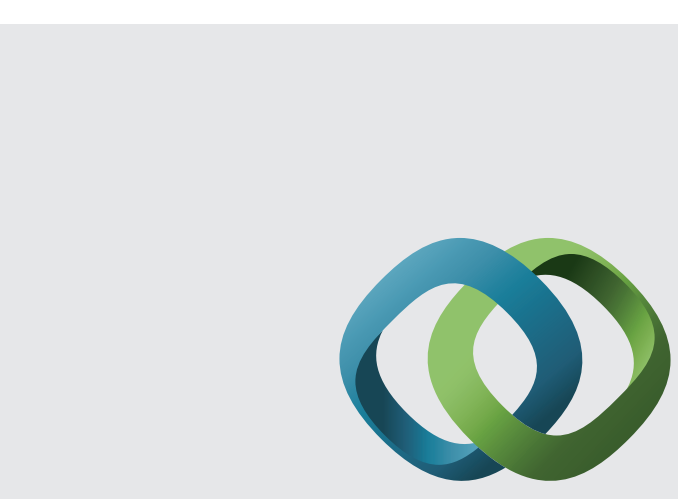

\section{Hindawi}

Submit your manuscripts at

http://www.hindawi.com
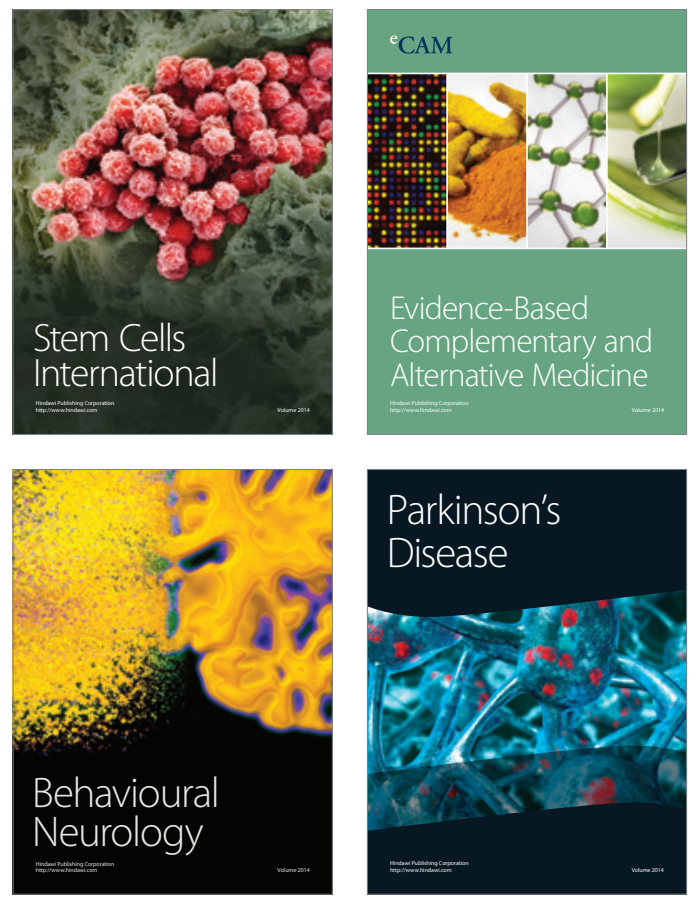
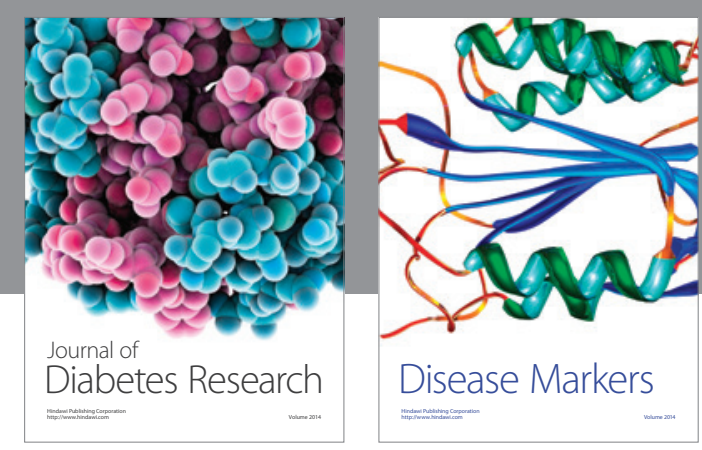

Disease Markers
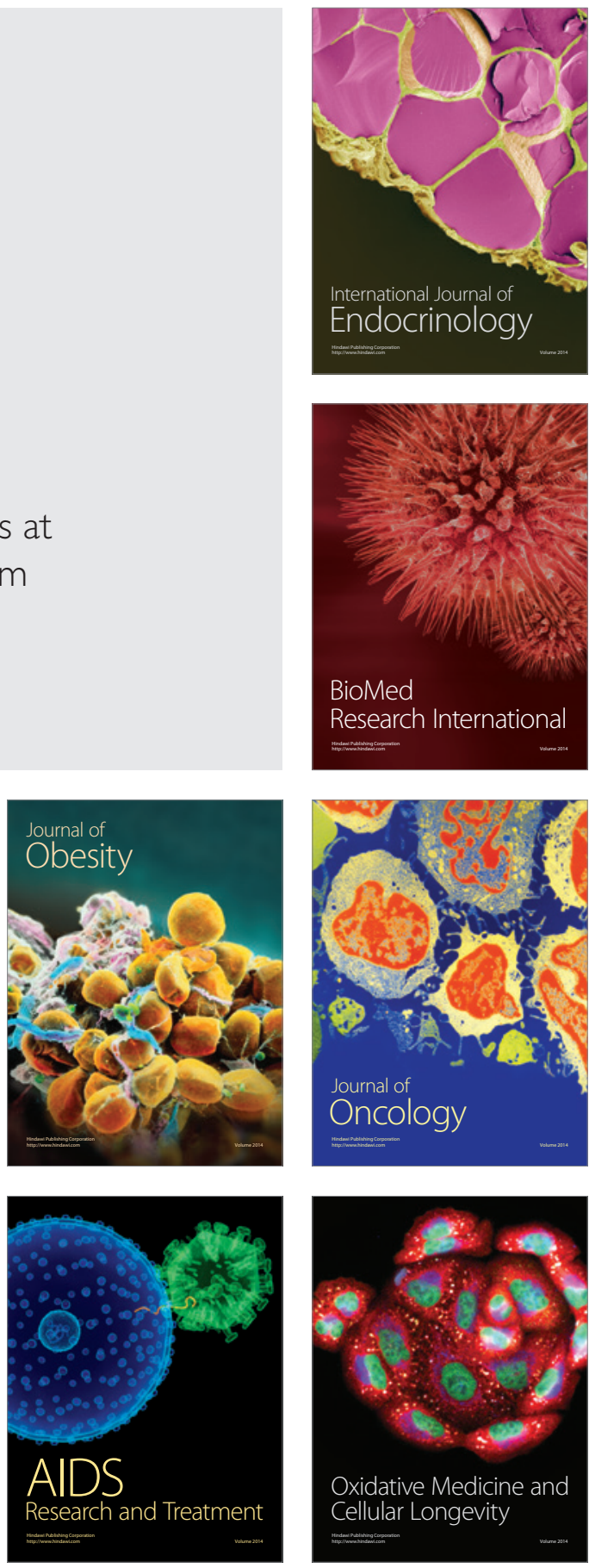